\title{
Chronic obstructive pulmonary disease affects angiographic presentation and outcomes
}

To the Editor We read with interest the study by Januszek et $\mathrm{al}^{1}$ reporting that chronic obstructive pulmonary disease (COPD) affects the angiographic presentation and outcomes of patients with coronary artery disease treated with percutaneous coronary interventions. ${ }^{1}$ We would like to discuss 3 issues.

First, in a multivariate analysis, the authors showed that smoking was one of the predictors of in-stent thrombosis, but they did not reveal whether it was also a predictor of restenosis. Instead, they reported 6 diseases, including COPD, to be predictors of restenosis. We agree with the results of the multivariate analysis; however, it would be interesting to know how the authors evaluated confounding variables between smoking and COPD. If there were no confounders, then it would be interesting to know what mechanism of COPD is associated with predicting restenosis. Does COPD itself cause blood vessel damage? Are sarcopenia and a reduction in muscle mass in patients with COPD associated with restenosis?

Second, the authors cited an article by Alessandri et $\mathrm{al}^{2}$ and described that COPD itself was considered to be a prothrombotic state. According to Alessandri et al, ${ }^{2}$ patients with COPD have an ongoing prothrombotic state, which could potentially explain the development of thrombosis in pulmonary vessels. It would be interesting to know if Januszek et $\mathrm{al}^{1}$ consider cardiovascular and pulmonary blood vessels to be the same.

Third, the authors cited an article by Enriquez et $\mathrm{al}^{3}$ and reported that patients with COPD were significantly less likely to receive $\beta$-blockers, aspirin, and statins at discharge after percutaneous coronary intervention. They concluded that special care in terms of the treatment of COPD is needed, which may improve long-term outcomes after PCI. It would be interesting to know if by "special care" the authors mean a more frequent administration of the drugs.

Author names and affiliations Tomohiro Tamura, Eiji Ojima, Hajime Osawa, Hiroaki Satoh (TT, HO, HS: Division of Respiratory Medicine, Mito Medical Center, University of Tsukuba, Mito, Japan; EO: Division of Cardiology, Mito Medical Center, University of Tsukuba, Mito, Japan)
Corresponding author Hiroaki Satoh, MD, $\mathrm{PhD}$, Division of Respiratory Medicine, Mito Medical Center, University of Tsukuba, Miya-machi 3-2-7, Mito, Ibaraki, 310-0015, Japan, phone: +81 29231 2371, email: hirosato@md.tsukuba.ac.jp

Conflict of interest The authors declare no conflict of interest.

How to cite Tamura T, Ojima E, Osawa H, Satoh H. Chronic obstructive pulmonary disease affects angiographic presentation and outcomes. Pol Arch Intern Med. 2018; 128: 195. doi: 10.20452/ pamw.4236.

\section{REFERENCES}

1 Januszek R, Siudak Z, Dziewierz A, et al. Chronic obstructive pulmonary disease affects the angiographic presentation and outcomes of patients with coronary artery disease treated with percutaneous coronary interventions. Pol Arch Intern Med. 2018; 128: 915-925.

2 Alessandri C, Basili S, Violi F, et al. Hypercoagulability state in patients with chronic obstructive pulmonary disease. Chronic Obstructive Bronchitis and Haemostasis Group. Thromb Haemost. 1994; 72: 34-346.

3 Enriquez JR, Parikh SV, Selzer $F$, et al. Increased adverse events after percutaneous coronary intervention in patients with COPD: insights from the National Heart, Lung, and Blood Institute dynamic registry. Chest. 2011; 140: 604-610.

Authors' reply In response to the first question, the smoking group included current smokers, while in the group with chronic obstructive pulmonary disease (COPD), we included patients with diagnosed COPD, in whom the inflammatory process had been maintained for many years due to previous or current exposure to tobacco smoke, and had been chronically treated with bronchodilators or, additionally, with anti-inflammatory drugs.

Several previous studies reported the role of inflammatory processes and their mechanisms in COPD. ${ }^{1}$ Not all smokers have developed a chronic inflammatory process in the airways, and even more so, not all have been diagnosed with COPD. However, active smokers seem to be more exposed to increased concentrations of oxidative stress markers than nonsmokers with long-term COPD, which may affect the mechanisms associated with stent thrombosis and restenosis. The role of inflammation has also been demonstrated in patients with sarcopenia and COPD, who showed 
a higher percentage of cardiovascular comorbidity and levels of systemic inflammatory markers. $^{2}$ Due to the lack of data on height in our database, we could not calculate body mass index; moreover, we did not perform bioelectrical impedance analysis and muscle handgrip strength measurements.

However, in the overall group of patients, the mean weight was lower in the subgroup of patients with $C O P D(P<0.001)$, without in-stent thrombosis at baseline $(P=0.01)$, and without restenosis at baseline $(P<0.001)$. The mean weight was also lower in the subgroup of patients with COPD previously treated with percutaneous coronary intervention $(P=0.03)$. Contrary to the overall group, the mean weight was lower in patients with in-stent thrombosis $(P=0.001)$ and restenosis $(P=0.03)$ at baseline. This indicates that lower weight in patients with COPD is related to higher rate of in-stent thrombosis and restenosis at baseline in the subgroup of patients previously treated with percutaneous coronary intervention.

Regarding the second question, the mechanisms of venous and arterial thrombosis seem to be different. Patients with COPD exacerbation showed a significantly increased risk of venous thrombosis, which is mainly explained by a transient aggravation of inflammatory processes, enhanced oxidative stress, and prothrombotic state including increased thrombin generation. ${ }^{3}$ In contrast, the increased risk of arterial thrombosis seems to be more due to endothelial dysfunction and platelet hyperreactivity, which has been shown in patients with stable COPD. ${ }^{4}$ Platelet activation was found to predict an adverse outcome in patients with stable coronary artery disease and to be related to recurrent cardiovascular events following percutaneous coronary intervention. ${ }^{5,6}$

In response to the third question, a number of published studies demonstrated poor compliance in patients with COPD, especially those who have difficulty quitting smoking. ${ }^{7}$ We also observed that smokers with COPD more often than nonsmokers tend to stop pharmacological treatment prematurely after revascularization, and sometimes they even do not take aspirin and statin, not to mention dual antiplatelet therapy. They also tend to discontinue the use of bronchodilators and return to them only in case of COPD exacerbation. Special care means, at least, a longer follow-up and more frequent visits. Moreover, patients should be encouraged to undergo regular pulmonary checkups and to stop smoking if they have not done so already.

Author names and affiliations Rafał Januszek, Zbigniew Siudak, Artur Dziewierz, Tomasz Rakowski, Dariusz Dudek, Stanisław Bartuś (RJ, AD, TR, DD, SB: 2nd Department of Cardiology and Cardiovascular Interventions, University Hospital, Kraków, Poland; ZS, DD: Department of Interventional Cardiology, Jagiellonian University
Medical College, Kraków, Poland; AD, AR, SB: 2nd Department of Cardiology, Jagiellonian University Medical College, Kraków, Poland)

Corresponding author Rafał Januszek, MD, PhD, II Oddział Kliniczny Kardiologii oraz Interwencji Sercowo-Naczyniowych, Szpital Uniwersytecki, ul. Kopernika 17, 31-501 Kraków, Poland, phone: +48 1242471 70, email: jaanraf@interia.pl

Conflict of interest The authors declare no conflict of interest.

How to cite Januszek R, Siudak Z, Dziewierz A, et al. Chronic obstructive pulmonary disease affects angiographic presentation and outcomes. Authors' reply. Pol Arch Intern Med. 2018; 128: 195-196. doi:10.20452/pamw.4237.

\section{REFERENCES}

4 Barnes PJ, Shapiro SD, Pauwels RA. Chronic obstructive pulmonary disease: molecular and cellular mechanisms. Eur Respir J. 2003; 22: 672 688. Byun MK, Cho EN, Chang J, et al. Sarcopenia correlates with systemic inflammation in COPD. Int J Chron Obstruct Pulmon Dis. 2017; 12 : 669-675. ¿

5 Mejza F, Lamprecht B, Niżankowska-Mogilnicka E, Undas A. Arterial and venous thromboembolism in chronic obstructive pulmonary disease: from pathogenic mechanisms to prevention and treatment. Pneumonol Alergol Pol. 2015; 83: 485-494.

6 Maclay JD, McAllister DA, Johnston S, et al. Increased platelet activation in patients with stable and acute exacerbation of COPD. Thorax. 2011; 66: 769-774. 5

7 Christie DJ, Kottke-Marchant K, Gorman RT. Hypersensitivity of platelets to adenosine diphosphate in patients with stable cardiovascular disease predicts major adverse events despite antiplatelet therapy. Platelets. 2008; 19: 104-110. ¿

8 Gianetti J, Parri MS, Sbrana S, et al. Platelet activation predicts recurrent ischemic events after percutaneous coronary angioplasty: a 6 months prospective study. Thromb Res. 2006; 118: 487-493. ¿

9 Dziewierz A, Siudak Z, Rakowski T, et al. Relationship between chronic obstructive pulmonary disease and in-hospital management and outcomes in patients with acute myocardial infarction. Kardiol Pol. 2010; 68: 294-301.

OPEN ACCESS This is an Open Access article distributed under the terms of the Creative Commons Attribution-NonCommercial-ShareAlike 4.0 International (CC BY-NC-SA 4.0) License (http://creativecommons.org/licenses/by-nc-sa/4.0/), allowing third parties to copy and redistribute the material in any medium or format and to remix, transform, and build upon the material, provided the original work is properly cited, distributed under the same license, and used for noncommercial purposes only. For commercial use, please contact the journal office at pamw@mp.pl. 